\title{
PEMANFAATAN MEDIA INFORMASI TEKNOLOGI DAN KOMUNIKASI DALAM PEMBELAJARAN PAI DI SEKOLAH DASAR
}

\author{
Resmi Perwita \\ Program Pascasarjana Universitas Muhammadiyah Sumatera Barat \\ resmiperwita@gmail.com
}

\begin{abstract}
The learning process is the delivery of information from teachers to students. Information conveyed in the form of science, skills and attitudes. In order for teaching materials to be delivered properly and quickly understood by students, media is needed to assist teachers in providing materials to students. The lesson of islamic religious education is a very useful learning for human life because it relates to life in the hereafter. ICT media can be used in the learning process. The use of ICT media in the material of the example story of Nuh (a) through video views of the example of Nuh as. The use of ICT media in learning to understand the story of Nuh's example makes it easy for students to understand the story of Nuh's example as well as students feel happy and comfortable in learning. So that the quality of islamic religious education learning can be improved by empowering ICT media. The purpose of this research to know ict media can improve the quality of islamic religious education lessons in the example story material of prophet Nuh as at SDN 08 six districts Padang Pariaman. From the observations seen there was a change from a value of 57.07 to 76.72. The use of ICT media in islamic religious education lessons in the story of the example of Nuh as has increased. The noticeable improvement is the improvement of the learning outcomes, the learning process, as well as the attitude of the students.
\end{abstract}

Keywords: learning quality; PAI, ICT Media

\begin{abstract}
Abstrak
Proses pembelajaran merupakan penyampaian informasi dari guru kepada siswa. Informasi yang disampaikan dalam bentuk ilmu pengetahuan, keterampilan dan sikap. Agar bahan ajar tersampaikan dengan baik dan cepat dipahami oleh siswa maka diperlukan media untuk membantu guru dalam memberikan materi kepada siswa. Pelajaran pendidikan agama islam merupakan pembelajaran yang sangat bermanfaat bagi kehidupan manusia karena berkaitan dengan kehidupan di akhirat. Media TIK dapat digunakan dalam proses pembelajaran. Pemanfaatan media TIK pada materi cerita percontohan Nuh (a) melalui tayangan video contoh Nuh as. Penggunaan media TIK dalam pembelajaran memahami cerita teladan Nuh memudahkan siswa dalam memahami cerita teladan Nuh serta siswa merasa senang dan nyaman dalam belajar. Sehingga kualitas pembelajaran pendidikan agama islam dapat ditingkatkan dengan pemberdayaan media TIK. Tujuan dari penelitian ini adalah untuk mengetahui media IKT yang dapat meningkatkan kualitas pembelajaran pendidikan agama islam pada materi contoh cerita nabi nuh di SDN 08 enam kabupaten Padang Pariaman. Dari hasil observasi terlihat terjadi perubahan dari nilai 57.07 menjadi 76.72. Pemanfaatan media TIK dalam pelajaran pendidikan agama islam dalam cerita teladan nuh semakin meningkat. Peningkatan yang terlihat adalah peningkatan hasil belajar, proses pembelajaran, serta sikap siswa.

Kata kunci: kualitas pembelajaran; PAI, Media ICT
\end{abstract}




\section{PENDAHULUAN}

Mutu pendidikan di Indonesia masih dianggap belum sesuai dengan yang diharapkan (Sukasni \& Efendy, 2017), (Zulfikar, 2009). Hal yang demikian dapat diketahui dari kemauan menuntut ilmu siswa, kesadaran untuk bersekolah, tidak jarang di antara peserta didik yang tidak perduli untuk mengikuti proses pembelajaran secara baik dan benar (Putri et al., 2017), (Busmayaril \& Umairoh, 2018). Di samping itu, kesiapaan dalam mengarungi lapangan usaha karena kurangnya kemampuan yang dimiliki oleh lulusan lembaga pendidikan (Subijanto, 2019).

Realita pendidikan Indonesia di atas erat kaitannya dengan berbagai aspek, seperti media pembelajaran yang digunakan (Susanti et al., 2020), metode pembelajaran (Hakim \& Ritonga, 2018), (Aprianto et al., 2020), sumber belajar (Ritonga, 2017), kompetensi guru (Tisnelly et al., 2020), (Hotmaida et al., 2020). Sejalan berkembangnya pengetahuan yang diiringi kemajuan dalam bidang pendidikan, kebutuhan akan sumber daya manusia sangat mendesak. Beragam cara diupayakan pemerintah untuk menaikkan keterampilan dan kemampuan melalui bidang pendidikan. Struktur yang telah diciptakan selama beberapa tahun terakhir ini, ternyata masih belum bisa untuk mewujudkan perubahan serta menjawab kemauan nasional dan secara keseluruhan. Tindakan menyerasikan dan meningkatkan pendidikan merupakan pusat pembentukan masih menjadi permasalahan yang belum mampu dituntaskan dalam bidang pendidikan.

Dalam proses belajar mengajar di zaman serba canggih dan digital ini, masih banyak di antara guru yang masih melakukan kegiatan pembelajaran dengan pola lama (Ritonga et al., 2016), seperti melalui ceramah, dan kurang memberdayakan media serta kurang menvariasikan sekian banyak cara yang bisa digunakan dalam pembelajaran (Hotmaida et al., 2020). Pendidik hanya memberikanpengetahuan yang dimiliki kepada anak didik yang masih dianggap seperti gelas yang tak berisi yang selalu menunggu untuk diisi supaya penuh. Hal ini seiring dengan proses belajar yang memusatkan hanya terhadap peserta didik tanpa menuntut siswa untuk aktif serta hanya melakukan pembelajaran satu arah. akibatnya banyak di antara peserta didik yang tidak bersemangat, mengantuk, dan sering berbuat yang tidak sesuai dengan yang seharusnya dilakukan oleh siswa, serta kurangnya minat siswa memperhatikan serta mendalami pelajaran yang diberikan secara fokus dan teliti (Darling-hammond et al., 2020).

Pembelajaran di sekolah haruslah mempunyai daya tarik terhadap siswa yaitu melalui berbagai macam cara yang harus dimiliki dan ditempuh pendidik dalam menyampaikan bahan ajar. Untuk itu sangat dibutuhkan peran media pembelajaran agar bahan ajar dapat tersampaikan secara maksimal (Puspitarini \& Hanif, 2019). Adapun hal yang bisa dilakukan agar pembelajaran terasa menyenangkan yaitu menggunakan media pembelajaran yang sesuai serta disukai oleh peserta didik yang berkembang sesuai perkembangan teknologi serta informasi yang sangat dibutuhkan untuk menyampaikan materi dengan baik supaya dikenal (Puspitarini \& Hanif, 2019). Sehingga dengan adanya media pelajaran dapat memperlancar proses serta mempercepat laju penyampaian materi pembelajaran oleh guru dalam menyalurkan ilmu pengetahuan.

Pembelajaran PAI memiliki posisi sangat penting di setiap jenjang pendidikan, maka pembelajaran PAI membutuhkan media tepat dalam menyampaikan materi ajar PAI mewujudkan anak yang memiliki akhlak yang 
baik serta mampu bersosialisasi dengan baik baik dirumah dan dilingkungan. Adapun langkah yang dapat dilakukan melalui pembaharuan kegiatan menyampaikan materi dalam bentuk pembiasaan melakukan penyampaian bahan ajar pendidikan agama islam dengan penggunaan media yang berdasarkan teknologi dan komunikasi juga disebut dengan media ICT (Ritonga et al., 2016) (Ritonga et al., 2020). Diharapkan penggunaan media ICT pelajaran pendidikan agama Islam bisa bersaing menjadi mata pelajaran yang mampu mengimbangi mata pelajaran lain serta selalu disenangi dan diminati serta mampu mengikuti dan menyesuaikan dengan perkembangan zaman serta tuntutan zaman.

Media ICT merupakan media yang digunakan dalam kegiatan mengajar, pembelajaran PAI menuntut adanya berbagai jenis dan macam media pembelajaran. Sehingga pembelajaran pendidikan agama Islam tersampaikan dengan baik kepada siswa. Adapun pertimbangan yang harus diperhatikan dalam penggunaan media pembelajaran berbasis ICT yaitu suatu yang ingin dicapai, tingkah laku atau sikap siswa, tujuan pelajaran yang diinginkan, model media yang dibutuhkan seperti media yang di dengar (audio) (Sartika \& Ritonga, 2020), media yang dilihat (visual) dilihat dan didengar (audio visual), kondisi lingkungan sekitar, keadan kondisi tempat belajar, serta cakupan yang harus diperoleh. Beberapa hal tersebut harus dipenuhi serta dipertimbangkan sebelum menggunakan media pembelajaran agama dengan menggunakan media ICT.

Media pembelajaran bebasis teknologi atau ICT dalam penggunaannya sangat membutuhkan ketersediaan internet (Ratheeswari, 2018). Internet sangat membantu dalam mencari informasi yang dibutuhkan baik dalam keadaan biasa maupun keadaan yang sangat mendesak (Lahmi et al., 2020). Dasar penggunaan sarana internet berfungsi sebagai pendamping media ICT, maka ada faktor yang harus diperhatikan seperti; lingkungan, meliputi lembaga yang beperan dalam penyeleggaraan pendidikan serta anggota lingkungan sekitar, orang yang akan didik yaitu peserta didik meliputi; umur, keadaan siswa, kebiasaan, bahasa yang digunakan, dan pola dan cara belajar, Guru atau pendidik, meliputi keadaan guru, umur, cara mengajar, berpengalaman, dan pribadi, teknologi, mencakup; komputer, infocus, serta perangkat lainnya. Penghubung ke internet, serta pengetahuan dan ketrampilan guru dalam penerapan internet di lingkungan sekolah.

Di SDN 08 Enam Lingkung Kabupaten Padang Pariaman kegiatan pembelajaran sudah menerapkan kurikulum 2013 kemampuan siswa dalam beraktivitas dalam proses pembelajaran pendidikan agama islam. Siswa dituntut dalam berbagai aspek penilaian mulai dari spiritual, sosial, pengetahuan serta keterampilan yang harus dimiliki. Kemampuan guru mempergunakan media yang gampang menemukannya dan sederhana dalam penggunaannya, sehingga tercapai tujuan pembelajaran pendidikan agama islam yang diharapkan yaitu tercipta nya insan yang memiliki keimanan serta takut kepada penciptanya. Guru pendidikan agama Islam di SDN 08 Enam Lingkung sudah berupaya mengoptimalkan pemanfaatan media pembelajaran. Hal yang sudah dilakukan seperti melengkapi ketersedian kelegkapan yang menunjang proses belajar mengajar meliputi ketersediaan laptop, LCD Proyektor, dan speaker aktif. Hal ini dilakukan agar peningkatan kualitas pembelajaran Pendidikan Agama Islam di SDN 08 Enam Lingkung Kabupaten Padang Pariaman. 


\section{METODOLOGI}

Untuk melakukan penelitian ini peneliti menggunakan penelitian kualitatif, teknik ini dipilih karena keinginan peneliti untuk mengungkapkan makna yang terdapat dalam realita di lokasi penelitian, realita yang dimaksud ialah kondisi nyata tentang kualitas pembelajaran yang dilaksanakan dengan memanfaatkan media ICT. Oleh sebab itu, sebagaimana layaknya penelitian kualitatif, data penelitian ini didapatkan melalui teknik observasi, wawancara dan studi terhadap dokumen terkait. Sumber penelitian ini ialah guru PAI, kepala sekolah, beberapa orang peserta didik yang dipilih secara purposive, penggunaan teknik purposive ini dimaksudkan agar peneliti tetap mengumpulkan data sebelum data dianggap cukup.

Secara operasionalnya, observasi peneliti gunakan untuk melihat kondisi alami pelaksanaan pembelajaran dengan menggunakan media ICT di Sekolah dasar, adapun hal-hal yang diamati ialah meliputi proses pembelajaran, aktifitas guru, aktifitas peserta didik serta realita lain yang ada di lokasi penelitian. Adapun wawancara digunakan ialah wawancara tidak terstruktur, penggunaan jenis wawancara ini dimaksudkan agar peneliti lebih leluasa untuk menanyakan kepada informan tentang pembelajaran PAI yang dilaksanakan menggunakan media ICT. Studi dokumentasi yang peneliti gunakan ialah melakukan analisis terhadap dokumen-dokumen pembelajaran PAI yang dikhususkan pada keterkaitan muatan dokumen dengan pembelajaran PAI menggunakan media ICT.

Data penelitian kemudian dianalisis dengan pendekatan kualitatif, dalam penelitian ini sejak pengumpulan data peneliti sebenarnya sudah mulai melakukan analisis dengan membuat klasifikasi data, namun untuk memastikan penarikan kesimpulan benar peneliti melakukan analisis data penelitian sebagaimana layaknya penelitian kualitatif. Pegujian keabsahan data penelitian ini dilakukan dengan mengandalkan teknik triangulasi.

\section{HASIL PENELITIAN DAN PEMBAHASAN}

Pada pengamatan awal di SDN 08 Enam Lingkung Kabupaten Padang Pariaman, penulis melihat guru PAI mengajar menggunakan metode ceramah serta kurangnya penggunaan media pelaran Pendidikan Agama Islam. Dalam mengikuti pembelajaran guru yang melaksanakan proses belajar hanya menggunakan papan tulis yang banyakdigunakan seperti biasa. Bisa dikatakan masih minimnya penggunaan media serta masih sering dan banyak menggunakan metode ceramah.

Berdasarkan wawancara penulis dengan Kepala SDN 08 Enam Lingkung Kabupaten Padang Pariaman menyatakan bahwa sekolah telah menyediakan media berupa laptop dan infokus untuk menunjang proses belajar dan memperoleh nilai seperti yang diharapkan. Kemudian beliau menambahkan Sebagian besar guru-guru di SDN 08 Enam Lingkung sudah bisa menggunakan laptop. Dan kami sebagai kepala sekolah sangat mendukung penggunaan media ini supaya anak dapat belajar dengan semangat serta mengkatkan prestasi dalam belajar.

Berdasarkan wawancara penulis dengan guru PAI di SDN 08 Enam Lingkung Padang Pariaman menyatakan bahwa menggunakan media dalam belajar bisa meningkatkan kreattivitas, motivasi, serta dibuktikan dengan rasa keingintahuan 
siswa tersebut. Sementara adapun kelemahan yang kami alami adalah waktu kurang mencukupi jika menggunakan media komputer dan laptop mulai dari pemasangannya hingga habis jam belajar, kemudian beliau juga menambahkan tidak semua pelajaran yang bisa digunakan media berbasis ICT. Dan terakhir beliau menyebutkan bahwa jumlah media infokus di sekolah kami juga minim, terkadang di gunakan oleh guru kelas dalam bersamaan dengan guru Pendidikan Agama Islam.

Dari hasil analisis terhadap dokumen terkait dengan kualitas pembelajaran PAI sebelum menggunakan media ICT ialah dapat digambarkan bahwa nilai yang dimiliki peserta didik pada materi kisah keteladanan nabi Nuh as nilai yang didapat dari jumlah peserta didik 26 siswa, hanya 1 orang yang memenuhi kriteria ketuntasan minimal, masih belum tuntas sebanyak 25 orang. Nilai tertinggi 80, nilai terendah yang diperoleh siswa 20 dengan nilai rata-rata 48,84. Ketika dikonfirmasi perolehan nilai ini guru PAI menyatakan bahwa perolehan itu adalah nyata disebabkan media pembelajaran saat itu belum maksimal dimanfaatkan.

Selanjutnya menurut guru PAI, setelah dimanfaatkan media ICT dalam pembelajaran PAI baru dua kali pertemuan sudah terdapat peningkatan dari sebelum dimanfaatkannya media ICT, pertama penilaian belajar peserta didik yang berjumlah 26 mencapai yang sudah mencapai Ketuntasan mengalami peningkatan yang baik sebanyak 10 siswa belum tuntas 16 siswa, nilai teratas 100 dan nilai terendah 70 dengan nilai rata-rata 65,30. Kegiatan pembelajaran pada pada tahap selanjutnya masih terlihat belum ada perkembangan serta perubahan aktivitas belajar siswa, sehingga butuh percobaan untuk tahap berikutnya. Agar memudahkan siswa memahami materi pembelajaran dan lebih bersemangat dalam pembelajaran pendidikan Agama Islam.

Kemampuan siswa dalam pelaksanaan pembelajaran selanjutnya menunjukkan bahwa pemahaman pembelajaran mengenai memahami keteladanan kisah nabi Nuh as,masih banyak diatara siswa yang belum tuntas sesuai dengan ketuntasan yang diharapkan serta memenuhi standar peningkatan yang diinginkan.Untuk melihat perkembangan berikutnya maka penulis memutuskan untuk melanjutkan penelitian ke tahap berikutnya.

Pelaksanaan tahapan ini terlihat perubahan proses pembelajaran dari tahap sebelumnya. Kemampuan belajar sebelum digunakannya media ICT dari 26 siswa, mencapai ketuntasan belajar 12 orang dengan nilai ratat-rata 65,76 sedangkan pada setelah dimanfaatkan media ICT dari 26 siswa mencapai ketuntasan 25 siswa dengan rata-rata 87,69. Kemampuan dari 26 siswa dengan skor tertinggi 100 dan terendah 80 . Proses pembelajaran pada tahap II sudah menunjukkan perubahan peningkatan dari pembelajaran sebelumnya. Ini dilihat dari berbagai aspek dintaranya :

1. Guru sudah bagus dalam penggunaan media pembelajaran yaitu media ICT sehingga memotivasi siswa dan tertarik dalam belajar kisah Nabi Nuh as

2. Guru sudah melakukan proses kegaiatan pembelajaran PAI mengenai keteladanan nabi Nuh as sesuai dengan standar kompetensi dan tujuan yang diharapkan.

3. Ketuntasan belajar sudah mencapai $100 \%$, dengan nilai minimal 80 dan maksimal 100 
4. Terciptanya perubahan serta perkembangan pembelajaran PAI dari tahap pembelajaran pertama skor rata-rata diperoleh 57,07 serta tahap pembelajaran kedua skor rata-rata 76,72. Perkembangan tersebut memperllihatkan bahwa ada peningkatan dalam pembelajaran PAI.

Pembelajaran pendidikan Agama Islam mengalami perobahan baik dari segi pengetahuan maupun keterampilan dengan menggunakan media berbasis ICT serta dan sudah memenuhi indikator yang peneliti harapkan. Peseerta didik sudah memperlihatkan peningkatannya dengan berbagai perubahan yang dialami peserta didik sendiri yaitu berupa perubahan nilai, perubahan sikap dalam yang dapat dilihat dari kemampuan siswa itu sendiri. Peneliti memutuskan untuk tidak melanjutkan ke tahap berikutnya, sebab peneliti melihat sudah ada peningkatkan kualitas pembelajaran Pendidikan Agama Islam dengan menggunakan media pembelajaran berbasis ICT di yang peneliti lakukan di SDN 08 Enam Lingkung kecamatan Enam Lingkung Kabupaten Padang Pariaman

\section{Pembelajaran PAI dengan Pemanfataan Media Berbasis ICT di SDN 08 Enam Lingkung Kabupaten Padang Pariaman}

Dalam kegiatan belajar pendidikan agama Islam beberapa unsur yaitu pendekatan, strategi, metode, media, sumber belajar, serta evaluasi pembelajaran. Agar pembelajaran berlangsung dengan baik serta siswa yang menerima juga dapat memahami dengan baik maka seorang guru harus mampu menyesuaikan dan menggunakan unsur tersebut. Media pembelajaran yang digunakan oleh guru harus disesuaikan dengan yang akan menerima materi.

Seiring berkembangnya ilmu pengetahuan pendidikan juga berupaya melakukan pembahruan dan memanfaatkan teknologi dalam proses belajar mengajar dalam menunjang tujuan pendidikan umumnya. Dalam hal ini peran guru sangatlah dibutuhkan dalam menjalankan teknologi tersebut, sehingga guru dituntut juga harus mampu dari segi pengetahuan dan keterampilan dalam memahami teknologi pendidikan tersebut. Kemampuan guru mengoperasikan serta menggunakan media pembelajaran dengan baik serta mengembangkan media pembelajaran tersebut dalam berbagai materi pelajaran.

Pemanfaatan media ICT dalam pembelajaran membutuhkan pengetahuan dan keterampilan, adapun kemampuan yang harus diperhatikan dalam penggunan media ICT yaitu:

a. Pengetahuan mengenai media

b. Pengetahuan tentang kegunaan media

c. Pengetahuan mengenai hal-hal yang dibutuhkan dalam pembelajaran.

d. Mengetahui keterkaitan strategi, metode mengajar dan media pembelajaran

e. Mengetahui kegunaan media pembelajaran dalam belajar

f. Mengetahui karakteristik media dalam pembelajaran.

g. Memahami macam-macam media dan alat yang dapat digunakan dalam pembelajaran

h. Mengetahui media yang cocok digunakan dalam setiap materi pelajaran Pendidikan Agama Islam.

i. Selalu mengikuti perkembangan dan berusaha melakukan pembaruan dalam kegiatan belajar. 
Media pembelajaran bukanlah fungsi tambahan dalam pembelajaran, tetapi merupakan alat yang berfungsi dalam penyampaian pelajaran sehingga media mempunyai peran penting dalam pembelajaran khususnya PAI, disamping itu media juga berperan sebagai moitivasi terhadap siswa untuk semangat dalam belajar serta meningkatkan prestasi dalam belajar.Guru SDN 08 Enam lingkung sudah mampu menggunakan media ICT secara keseluruhan. Sehingga dalam pembelajaran guru menggunakan media ICT dalam menyampaikan materi pelajaran. Guru tersebut merasa sangat terbantu jika menggunakan media dalam belajar, sehingga anak tidak cepat bosan serta tidak sering keluar masuk. Siswa SD sangatlah menyukai tontonan dengan menonton tayangan materi pelajaran siswa akan juga mudah memahami pembelajaran dengan baik.

Berdasarkan temuan di atas dapat diungkapkan bahwa pembelajaran PAI dalam tema keteladanan Nabi Nuh as dengan menggunakan media ICT memberikan hasil yang cukup menggembirakan, pemanfaatan media ICT sebagaimana hasil pengamatan yang peneliti lakukan lebih didominasi pada pembukaan youtube tentang kisah nabi Nuh as, beberapa di antara peserta didik yang diwawancarai mengungkapkan bahwa pembelajaran PAI dengan memanfaatkan media youtube meningkatkan motivasi bagi dirinya.

Hasil penelitian di atas sesuai dengan temuan para peneliti terdahulu yang menegaskan bahwa media pembelajaran yang dekat dengan peserta didik mampu membangkitkan semangat setiap peserta didik yang mengikuti pembelajaran (Sartika \& Ritonga, 2020). Peserta didik usia sekolah dasar dapat dikatakan membutuhkan berbagai strategi dan pendekatan yang variatif untuk menghilangkan kejenuhan dalam mengikuti pembelajaran, seperti pemilihan media pembelajaran yang tepat (Suprayogi \& Valcke, 2016), (Hakim et al., 2020). Atas dasar ini penggunaan media ICT dalam pembelajaran PAI untuk jenjang pedidikan dasar dapat dimaksimalkan guna meningkatkan kualitas pembelajaran.

\section{Peningkatkan kualitas pembelajaran PAI dengan Penggunaan Media Pembelajaran ICT di SDN 08 Enam Lingkung Kabupaten Padang Pariaman}

Media pembelajaran sangatlah banyak model dan ragamnya yang bisa digunakan dalam pembelajaran mulai dari manual maupun elektronik. Tidak tertutup kemungkinan menggunakan media yang bervariasi. Media pembelajaran semakin hari semakin berkembang dan meningkat. Media yang digunakan sekarang bervariasi seperti penggunaan komputer, infokus,speaker, rekaman, video, VCD player dan lain sebagainya. semua peralatan itu digunakan secara serentak, didengar suaranya dan dan dapat diamati.

Pemanfaatan ICT dalam pelajaran PAI sangat membantu dalam kegiatan bealajar. Pembelajaran PAI beragam materi mulai dari akidah, ibadah, al-qur'an, akhlak, muamalah, syariah, serta kisah kisah sejarah (tarikh). Materi seperti ini sangat membutuhkan media dalam menyampaikannya. Seperti contoh kisah Nabi Nuh as, kisah ini jika diberikan oleh guru secara bercerita atau ceramah saja siswa akan merasa cepat bosan dan terkadang mengantuk, bahkan akan ribut jika dia menganggap cerita itu kurang bagus menurut dia. Dengan adanya media ICT guru pendidikan agama islam sangat merasa terbantu karena dengan video yang ditampilkan kisah nabi Nuh anak lebih senang dari pada di ceritakan lewat mulut saja. Media ini juga mengurangi tenaga guru agar tidak selalu berbicara, hanya saja guru memberikan kesimpulan serta penguatan terhadap anak setelah selesai 
menonton yang ditayangkan. Pembelajaran PAI merupakan masalah yang tidak bisa hanya dijelaskan dengan kata-kata, tetapi dampak serta pengaruhnya akan tampak dalam kehidupan yang nyata. Salah satu cara pembentukanya yaitu melalui lembaga pendidikan formal yang dikemas dalam pelajaran pendidikan agama islam, yang diajarkan disekolah melalui bermacam media yang digunakan termasuk media pembelajaran ICT untuk menkonkretkan dalam bentuk materi yang sifatnya abstrak. Sehingga dengan media ICT yang digunakan guru dapat meningkatkan kualitas pembelajaran PAI serta membentuk pribadi siswa yang mencermikan keimanan siswa kepada Allah swt .

Konstribusi Media Pembelajaran Berbasis ICT dalam meningkatkan pembelajaran Pendidikan Agama Islam di SDN 08 Enam Lingkung Kecamatan Enam Lingkung Kabupaten Padang Pariaman. Adapun bentuk konstribusi media ICT dalam proses belajar yaitu:

a. Materi lebih mudah untuk disampaikan

b. Kegiatan belajar menarik serta menyenangkan

c. Kegiatan belajar mengajar lebih aktif dan siswa bersemangat mengikutinya.

d. Pelaksanaan proses belajar lebih efektif

e. Dapat meningkatkan pembelajaran dan meningkatkan nilai belajar anak.

f. Kegiatan belajar terasa nyaman dan menyenangkan serta tidak terasa waktu berjalan berlalu.

g. Siswa bersikap positif menerima pembelajaran dan menyenangi materi tersebut

h. Guru memiliki sikap positif terhadap anak karena anak yang mengikuti pembelajaran dengan baik.

Saat ini guru mempunyai alat yang dikenal dengan ICT yang dapat menyediakan sumber daya yang lebih bervariasi dan responsif, beragam sehingga menarik minat. Media ICT mampu menjadi teman belajar yang sangat mungkin menjadi penting dalam memfasilitasi guru dalam konteks ini. Keterlibatan secara aktif dengan artefak digital dapat memperkaya dan memperkuat pemahaman guru tentang konten dan bagaimana cara membelajarkannya. Dalam arti, guru abad 21 harus mampu berpikir untuk mendesain cara-cara belajar dalam perspektif baru, diantaranya bagaimana mengkondisikan peserta didik untuk belajar memperoleh berbagai pengetahuan dengan memanfaatkan ICT. Guru yang mampu menciptakan berbagai aktivitas belajar yang menantang kreativitas peserta didik, membuat dampak yang nyata pada pserta didiknya, memiliki pemahaman materi secara mendalam dan komprehensif, memiliki pengetahuan dan keterampilan paedagogis yang baik, memiliki antusias yang dapat menularkan motivasi belajar pada peserta didik, menyediakan lingkungan belajar yang memenuhi kebutuhan individu peserta didik.

Pada umumnya proses belajar yang dilakukan guru pada saat ini salah satunya bertujuan agar menghasilkan individu-individu yang inovatif, banyak akalnya, bisa memecahkan masalah sulit, senang melihat impilikasi yang baru, percaya diri, dan berani mengambil resiko.

Adapun manfaat penggunaan media menjadikan nyata materi pembelajaran yang kurang mampu siswa menelaahnya menjadi terlihat dan mampu menganalisa pelajaran tersebut misalnya untuk menjelaskan tentang kisah keteladanan nabi Nuh as bisa menggunakan media laptop yang ditayangkan video kisah keteladanan nabi Nuh as. Sehingga siswa dapat melihat bagaimanan kisah 
Nabi Nuh as melalui tayangan video tersebut dan bisa membayangkan apa dan bagaimana kisah nabi Nuh tersebut. Kemudian dapat memahami sifat dan keteladanan yang bisa dicontoh dari nabi Nuh as.

Penggunaan media berbasis ICT di SDN 08 Enam lingkung memberikan konstribusi yang besar dalam pembelajaran yaitu: mempermudah menyampaikan materi, guru merasa terbantu dan mengurangi tenaga guru, mempermudah siswa memahami materi karena dapat dilihat secara langsung, siswa merasa senang dengan menggunakan media sehingga mudah memahami materi pelajaran, serta siswa lebih bersemangat dalam belajar. Guru memiliki tanggungjawab untuk mengintegrsaikan ICT dalam proses pembelajaran maka dampak positfnya motivasi belajar peserta didik akan meningkat, bagi guru saat ini laptop merupakan bagian dari peralatan kelas. Selalu memperbaharui pengetahuan dan informasi sehingga menciptakan peserta didik yang berprestasi. Dalam hal ini nampak bahwa konstribusi media khususnya media ICT dalam pelajaran PAI mempunyai pengaruh yang besar serta meningkatkan kemauan serta kemampuan siswa dalam belajar.

\section{KESIMPULAN DAN SARAN}

Hasil temuan di SDN 08 Enam lingkung dapat diketahui bahwa pembelajaran menggunakan media ICT dapat meningkatkan kualitas pembelajaran PAI. Berdasarkan perkembangan aktivitas belajar serta hasil belajar yang terlihat selama penelitian, semuanya mengalami peningkatan sehingga memicu semangat dan kemauan siswa dalam belajar dan pembelajaran PAI pun akan disenangi sehingga dengan mudah dipahami dan dimengerti oleh siswa. Peningkatan kualitas itu terlihat dalam proses dan hasil pembelajaran PAI.

Bagi guru diharapkan untuk mempertahankan dan mengembangkan keterampilan dalam menggunakan media ICT sebagai media atau penyampai informasi dan pengetahuan agama terhadap siswa sehingga materi tersampaikan dengan baik dan maksimal kepada peserta didik.

\section{DAFTAR PUSTAKA}

Aprianto, Ritonga, M., Marlius, Y., \& Nusyur, R. (2020). The Influence of Using Audio- lingual Method on Students' Speaking Skill in Madrasah Diniyah Takmiliyah Awwaliyyah. Izdihar: Journal of Arabic Language Teaching, Linguistics, and Literature, 3(2), 149-162. https://doi.org/https://doi.org/10.22219/jiz.v3i2.12514

Busmayaril, \& Umairoh, E. (2018). Mengatasi Perilaku Membolos Peserta Didik Menggunakan Konseling Individual. Konseli (Jurnal Bimbingan Dan Konseling), $\quad$ 05(1), 35-44. https://doi.org/http://dx.doi.org/10.24042/kons.v5i1.2659

Darling-hammond, L., Flook, L., Cook-harvey, C., Barron, B., \& Osher, D. (2020). Implications for educational practice of the science of learning and development. Applied Developmental Science, 24(2), 97-140. https://doi.org/10.1080/10888691.2018.1537791

Hakim, R., Khadijah, Ritonga, M., Susanti, W., \& Rahmi. (2020). Institute Quality Improvement Through Management Training of Accreditation Preparation in TK Aisyiyah Bustanul Athfal Padang. Advances in Social Science, Education and Humanities Research, Volume 449 Proceedings of 
the International Conference of Early Childhood Education (ICECE 2019), 44(Icece 2019),

55-65. https://doi.org/https://doi.org/10.2991/assehr.k.200715.012

Hakim, R., \& Ritonga, M. (2018). A Study of Religion Education Method With Multicultural Insight. International Seminar on Islamic Education (ISIE 2018) Faculty of Islamic Religion, Universitas Muhammadiyah Ponorogo, July 07th, 2018, Isie 2018, 81-97.

Hotmaida, Ritonga, M., \& Mursal. (2020). Islamic Religious Education Learning at Elementary Schools: Analysis of Teacher Competency, Strategy and Outcome Quality. Ruhama: Islamic Education Journal, 3(2), 29-42. https://doi.org/https://doi.org/10.31869/ruhama.v3i2.2221

Lahmi, A., Ritonga, M., Saputra, R., Mursal, Ayu, S., Nurdianto, T., \& Afdhal, S. (2020). Internet, Pesantren and Management Strategies Educational Building. International Journal of Advanced Science Research, 29(4), 2827-2836. http://sersc.org/journals/index.php/IJAST/article/view/23459/12133

Puspitarini, Y. D., \& Hanif, M. (2019). Using Learning Media to Increase Learning Motivation in Elementary School. Anatolian Journal of Education, 4(2), 53-60. https://doi.org/10.29333/aje.2019.426a

Putri, M. S., Daharnis, \& Zikra. (2017). Hubungan Kontrol Diri dengan Perilaku Membolos Siswa. Konselor, 6(1), 1-5. https://doi.org/10.24036/02017616441-0-00

Ratheeswari, K. (2018). Information Communication Technology in Education. Journal of Applied and Advanced Research, 3(Suppl.1), 45-47.

Ritonga, M. (2017). Desain Bahan Ajar Bahasa Arab Sains dengan Pendekatan Whole Language. EDUKASI: Jurnal Pendidikan Islam, 5(2), 001-024. https://doi.org/https://doi.org/10.5281/edukasi.v5i2.287

Ritonga, M., Nazir, A., \& Wahyuni, S. (2016). Pembelajaran Bahasa Arab Berbasis Teknologi Informasi dan Komunikasi. Arabiyat: Jurnal Pendidikan Bahasa Arab Dan Kebahasaaraban, 3(1), 1-12. https://doi.org/http://dx.doi.org/10.15408/a.v3i1.2879

Ritonga, M., Nazir, A., \& Wahyuni, S. (2020). Pengembangan Model Pembelajaran Bahasa Arab Berbasis Teknologi Informasi \& Komunikasi dalam Dialektika Revolusi Industri 4.0. Deepublish. https://books.google.co.id/books?hl=id\&lr=\&id=OEXYDwAAQBAJ\&oi=fn $\mathrm{d} \& p g=P P 1 \&$ ots=sbr9Fjm_t\&sig=gqKsqW7fcokp_ya5MQd1zMZfQGE\&re dir_esc $=\mathrm{y} \# \mathrm{v}=$ onepage $\& \mathrm{q} \& \mathrm{f}=$ false

Sartika, F., \& Ritonga, M. (2020). Ta'tsir Isti'mal al-Wasa'il al-Sam'iyyah alBashariyyah "Ala Nataij Ta'lim Mufradat al-Lughah al-'Arabiyyah Lilfashl al-Rabi” fi al-Madrasah al-Ibtida'iyah al-Islamiyyah al-Hukumiyyah Parambahan Lambasi Payakumbuh. Alfazuna, 4(2), 144-154. http://jurnalftk.uinsby.ac.id/index.php/alfazuna/article/view/592/261

Subijanto. (2019). Perceptions of Workplace, Principal, and Productive Teachers on Students' Work Readiness in SMK Negeri 5 Surabaya Indonesia. Jurnal PTK: Research and Learning in Vocational Education, 2(4), 125-133.

Sukasni, A., \& Efendy, H. (2017). The Problematic of Education System in Indonesia and Reform Agenda. International Journal of Education, 9(3), 183-199. https://doi.org/10.5296/ije.v9i3.11705

Suprayogi, M. N., \& Valcke, M. (2016). Differentiated Instruction in Primary 
School: Implementation and Challenges in Indonesia. PONTE International Scientific Researchs Journal, 72(6), 1-18. https://doi.org/10.21506/j.ponte.2016.6.1

Susanti, E., Ritonga, M., \& Bambang, B. (2020). Pengaruh Penggunaan Media Powerpoint Terhadap Minat Belajar Bahasa Arab Siswa. Arabiyatuna: Jurnal Bahasa Arab, 4(1), 179-191. https://doi.org/10.29240/jba.v4i1.1406

Tisnelly, Ritonga, M., \& Rasyid, A. (2020). The Competency of Islamic Education Teachers in Madrasah Ibtidaiyah 1 West Pasaman After Certification. Ruhama: Islamic Education Journal, 3(1), 45-56. https://doi.org/https://doi.org/10.31869/ruhama.v3i1.1940

Zulfikar, T. (2009). The Making of Indonesian Education: An Overview on Empowering Indonesian Teachers. Journal of Indonesian Social Sciences and Humanities, 2, 13-39. http://www.kitlv-journals.nl/index.php/jissh/index URN:NBN:NL:UI:10-1-100135 